\title{
The Supply of Authorized Providers for Medication-Assisted Treatment in Ohio
}

\author{
Ariana Pitcher ${ }^{1}$; Wendy Yi Xu \\ ${ }^{1}$ College of Public Health, The Ohio State University, Columbus, $\mathrm{OH}$ \\ ${ }^{2}$ Division of Health Services Management and Policy, College of Public Health, The Ohio State University, Columbus, OH \\ Corresponding Author: Ariana Pitcher, 1841 Neil Ave., 250 Cunz Hall, Columbus, OH 43210, (815) 529-6587, apitcher@unc.edu \\ Submitted July 15, 2021 Accepted November 22, 2021 Published January 28, 2022 https://doi.org/10.18061/ojph.v4i2.8439
}

\section{ABSTRACT}

Background: Ohio experiences among the highest drug overdose rates nationally. The Drug Addiction Treatment Act (DATA) of 2000 permits qualified clinicians to use medication-assisted treatment (MAT) to treat opioid dependency. This study characterizes clinicians authorized to perform MAT and examines whether these clinicians are geographically collocated in areas with higher opioid burdens.

Methods: Data of DATA providers in 2019 came from the Substance Abuse and Mental Health Administration. Opioid overdose mortality rates were extracted from the County Health Rankings and Roadmaps to represent disease burdens in local areas. The DATA provider density is represented by the number of DATA-waivered providers per 100000 population for each county. We used Pearson correlational tests to examine the correlations between the local DATA provider density and the opioid mortality rate.

Results: Most of the DATA providers were physicians (57\%), followed by nurse practitioners (27\%) and physician assistants (4\%). The average waivered provider density was 13.90 per 100000 population. The local density of DATA providers and local opioid overdose death rates are moderately correlated $(P<0.001)$.

Conclusion: Physicians still represent most waivered providers in Ohio. While DATA providers were located in some areas with high needs for opioid treatments, our data suggest that other areas with high opioid burdens likely have an inadequate workforce supply to reduce opioid burdens. Without an adequate DATA workforce, policies that focus on MAT care access to address the opioid epidemic may be in vain.

Keywords: Drug Addiction Treatment Act (DATA); Health care workforce; Medication-assisted treatment; Opioid use disorder

\section{INTRODUCTION}

Today, Ohio stands among the top 5 states for the highest mortality rates due to drug overdoses. ${ }^{1}$ In the last 2 decades, the overall drug overdose rate in Ohio increased 9-fold compared to the national average increase of 3 -fold. ${ }^{2}$ To help tackle the opioid crisis, local and state governments pushed to expand medicationassisted treatment (MAT) with evidence of its ability to reduce drug overdose deaths. ${ }^{3}$ Medication-assisted treatment utilizes medications, such as methadone, buprenorphine, and naltrexone, alongside counseling and behavioral therapies to treat substance use disorders, including opioid and alcohol use disorders. ${ }^{1,4}$ Under the Drug Addiction Treatment Act of 2000 (DATA 2000), certain clinicians can obtain a waiver to prescribe MAT with buprenorphine or naltrexone outside of opioid treatment programs. 5 The DATA 2000 first only allowed physicians to be eligible for the waiver. The DATA waiver was later extended to other qualified clinicians under the Comprehensive Addiction and Recovery Act of 2016, such as nurse practitioners (NPs) and physician assistants (PAs), to also provide MAT. ${ }^{6}$

Despite policies to expand MAT treatment workforce, a national shortage in the availability of providers still exists. In 2017, approximately $46.4 \%$ of all US counties lacked an authorized clini- 
cian to prescribe MATs for opioid use disorders, a situation worse in rural counties $(71.6 \%) .{ }^{7}$ Over $30 \%$ of US counties did not have a single DATA waived provider in $2018 .{ }^{8}$ Few physicians, $3 \%$ of all primary care physicians (PCPs) and $16 \%$ of all psychiatrists, have ever obtained the DATA waiver, and most of them practice in urban areas. ${ }^{9}$ The severity of the opioid epidemic in Ohio demonstrates the urgency to examine whether DATA providers are geographically collocated in Ohio counties with higher opioid burdens. This information is critical for policy decisions that impact the allocation of state resources, workforce planning, and targeted interventions to reduce disparities. Without an adequate MAT provider workforce available, Ohio cannot possibly deliver vital treatments to the most vulnerable populations in need.

\section{METHODS}

\section{Design}

We conducted secondary data analyses with a cross-sectional design at the county level in Ohio to examine the correlation between DATA-waivered providers and opioid mortality rates.

\section{Data and Study Sample}

Waivered provider information was obtained from the 2019 SAMHSA buprenorphine waiver registration database. ${ }^{10}$ The database contained detailed information about practitioners with a DATA waiver, including their credentials such as medical doctors (MDs), doctors of osteopathy (DOs), PAs, and NPs, as well as the contacting information of each provider. Providers registered under multiple practice locations in the same county were counted as 1 provider. Providers practicing in multiple counties were counted as a separate provider under each county. The study sample included 2075 DATA-registered providers.

Data to measure the opioid burden were taken from the County Health Rankings and Roadmaps program of the Robert Wood Johnson Foundation. ${ }^{11}$ The 2015-2017 drug overdose deaths data in each Ohio county were used, which were based off a 3-year average, and these were the most updated data available during the study. The US Census Bureau data were used for the population counts. ${ }^{12}$

\section{Measures/Outcomes}

The DATA provider density was defined as the number of waivered providers per 100000 population in a county. We calculated a provider density measure for total DATA providers in a county, including all provider types. We also calculated a density for each of the 3 major provider types (physician, NP, and PA), respectively. The opioid burden is represented by the drug overdose mortality rates, defined as the number of drug poisoning deaths per 100000 population in a county. ${ }^{11}$ Drug poisoning deaths are deaths from accidental, incidental, and undetermined drug poisoning for the aggregate annual population over a 3-year period (2015-2017).11 The count of drug overdose deaths was utilized as an alternative measure of the opioid burden during robustness analyses. Four counties did not report any drug overdose deaths during the observation period and were coded as " 0 " in the drug burden measures.

\section{Statistical Analysis}

The DATA provider types were first characterized in each county. We studied the DATA provider distribution according to the drug use disease burden. The total DATA provider density was also ranked by counties. To gauge whether supply of MAT treatment workforce matches the local medical needs, Pearson correlation tests were applied to test the correlations between waivered provider density measures and opioid overdose rates. Strength thresholds picked for the Pearson correlational coefficient (R) were based on a scale commonly used in the social sciences. ${ }^{13} \mathrm{~A}$ robustness test was conducted using the counts of opioid deaths in a county. A 95\% confidence interval (CI) was used for all tests.

\section{RESULTS}

Figure 1 presents the distribution of all DATA-waivered providers by profession across all counties. MDs and DOs were combined into 1 group to represent total physicians. Most of the DATA providers in Ohio were physicians (57\%), followed by NPs $(27 \%)$. In the DATA registry, 259 providers did not specify their profession but were included in the analysis of total waivered providers for each county. These practitioners were authorized to prescribe MAT (12\%).

The average DATA provider density in a county, including all provider types, was 13.90 per 100000 population (SD 9.9; 95\% CI 11.7-16.1) with medium of 11.3 per 100000 population. There was a substantial variation in waivered provider density statewide. Waivered provider densities ranged from a minimum of 1.89 per 100000 to a maximum of 47.89 per 100000 population.

A moderate, statistically significant positive relationship was observed between the density of providers in a county and countylevel opioid overdose death rates $(\mathrm{r}(76)=.40, \mathrm{P} \leq .001)$. This may suggest that eligible providers in high need regions were more likely to obtain the DATA waivers. However, the correlation was moderate and, in many counties with high drug overdose death rates, waivered providers did not locate where the potential patients were located.

Measures in counties with the highest and lowest overdose rates were examined and compared (Table 1). The 5 counties with the highest overdose rates had much higher mean provider densities (20.50 per 100000 ) than the statewide average (13.90 per $100000)$. Scioto County had the highest DATA provider density in Ohio. Montgomery County had the highest overdose rate in all of Ohio and had the $10^{\text {th }}$ highest provider density compared to the sample average (26.11 versus 13.90 per 100000 population). Yet most of the top overdose counties did not have the highest waivered provider densities that matched their disease burden ranking. Some of the top overdose counties even had DATA provider densities comparable to the provider densities of the lowest dis- 


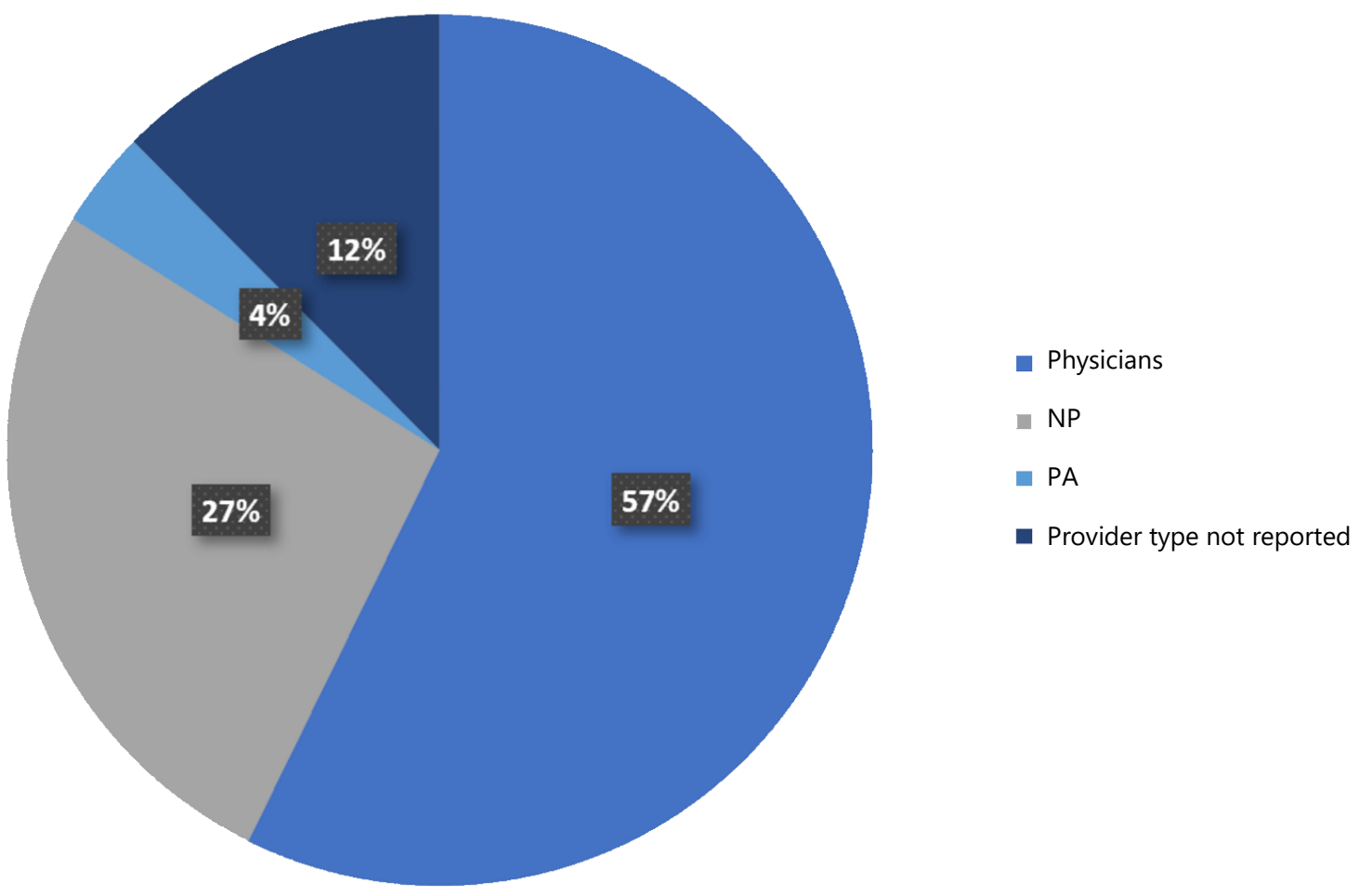

Figure 1. Distribution of DATA-Waivered Provider Types in Ohio

ease burden counties. This may raise some questions as to whether counties such as Clark, Butler, Trumbull and Brown, where the worse overdose death rates occurred, have an adequate supply of DATA-waivered providers to meet the disease burdens.

\section{Robustness Tests}

A sensitivity test varied overdose death rates with the counts of overdose deaths to understand if the correlation between opioid burden and total waivered provider density held. A weaker but statistically significant positive relationship was also found between total waivered provider density and the number of overdose deaths across counties ( $\mathrm{r}(76)=.31, \mathrm{P}=.006$; 95\% CI .09- .50). Although this effect was weaker, a significant correlation further validates a likely positive relationship between the supply of waivered providers and opioid burden.

\section{DISCUSSION}

Alleviating the opioid crisis in Ohio through better access to MAT treatment is a vital public health policy. Our study found a positive association between where providers who are authorized to deliver the treatment are located and areas with high opioid overdose rates. This finding implies that overall, providers in an area with higher opioid burden are more likely to obtain DATA waivers to expand capacity to provide treatment. These results are consistent with literature documenting a positive relationship between areas of greater treatment capacity and a higher opioid burden nationally. ${ }^{8}$ The average DATA provider density of 13.90 per 100000 population in Ohio, was smaller than the national average of $14.3 \mathrm{per}$ 100000 person. ${ }^{14}$ This places Ohio lower in provider supply com- pared to other states despite a more severe opioid epidemic, which demonstrates a necessity to expand MAT treatment provider workforce in Ohio.

Our study reveals that Ohio needs to improve the distribution of the MAT treatment workforce to serve drug dependency patients and to provide adequate care in areas where there is a high concentration of patients. Counties having the highest overdose rates did not possess high-ranking provider densities. This mismatch implies that having a high opioid burden may influence providers to obtain waivers in their county, but it has not strongly pushed providers to locate and practice where the highest needs are. The potential workforce shortages in Ohio will likely hamper the effectiveness of state or local policy efforts to expand the MAT treatment scale, leaving patients more vulnerable without sufficient care. Currently, Ohio is only able to treat $20 \%$ to $40 \%$ of the entire population abusing opioids or with drug dependence. ${ }^{2}$ About $20 \%$ of Ohio office-based treatment clinicians are not actively prescribing and one half of them deny insurance for their services. ${ }^{15}$ Our findings further add to the evidence base of provider maldistribution when poor accessibility prevents the ability to match treatment needs.

Furthermore, when understanding why providers did not obtain the DATA waiver in high need regions, it is possible that there has been a more severe shortage of clinicians in lower-income regions in general, as over one half of Ohio populations reside in areas with a shortage of primary care physicians. ${ }^{16}$ Many of these areas have high opioid fatalities. 
Table 1. Top Five Counties with Highest and Lowest Drug Overdose Death Rates

\begin{tabular}{|c|c|c|c|c|c|c|}
\hline $\begin{array}{l}\text { Counties with the } 5 \\
\text { Highest Drug } \\
\text { Overdose Rates }\end{array}$ & $\begin{array}{l}\text { Overdose } \\
\text { Death Rate } \\
\text { per } 100000\end{array}$ & $\begin{array}{l}\text { DATA Provider } \\
\text { Density } \\
\text { per } 100000\end{array}$ & $\begin{array}{l}\text { DATA Provider } \\
\text { Density } \\
\text { Ranking* }\end{array}$ & $\begin{array}{l}\text { DATA Physician } \\
\text { Density } \\
\text { per } 100000\end{array}$ & $\begin{array}{l}\text { DATA NP } \\
\text { Density } \\
\text { per } 100000\end{array}$ & $\begin{array}{l}\text { DATA PA } \\
\text { Density } \\
\text { per } 100000\end{array}$ \\
\hline 1. Montgomery & 70 & 26.11 & 10 & 13.52 & 7.33 & 1.31 \\
\hline 2. Clark & 62 & 15.60 & 25 & 8.17 & 3.72 & 2.23 \\
\hline 3. Butler & 60 & 14.65 & 28 & 8.11 & 5.75 & 0.78 \\
\hline \multirow{2}{*}{$\begin{array}{l}\text { 4. Trumbull } \\
\text { Brown }\end{array}$} & 57 & 12.08 & 35 & 7.55 & 3.52 & 0.50 \\
\hline & 57 & 6.88 & 61 & 2.29 & 4.59 & 0.00 \\
\hline 5. Scioto & 52 & 47.68 & 1 & 25.16 & 21.19 & 0.00 \\
\hline $\begin{array}{l}\text { Counties with the } 5 \\
\text { Lowest Drug } \\
\text { Overdose Rates }\end{array}$ & $\begin{array}{l}\text { Overdose } \\
\text { Death Rate } \\
\text { per } 100000\end{array}$ & $\begin{array}{l}\text { DATA Provider } \\
\text { Density } \\
\text { per } 100000\end{array}$ & $\begin{array}{l}\text { DATA Provider } \\
\text { Density } \\
\text { Ranking* }\end{array}$ & $\begin{array}{l}\text { DATA Physician } \\
\text { Density } \\
\text { per } 100000\end{array}$ & $\begin{array}{l}\text { DATA NP } \\
\text { Density } \\
\text { per } 100000\end{array}$ & $\begin{array}{l}\text { DATA PA } \\
\text { Density } \\
\text { per } 100000\end{array}$ \\
\hline 1. Morgan & 0 & 6.85 & 62 & 0 & 6.85 & 0 \\
\hline 2. Vinton & 0 & 7.61 & 55 & 0 & 7.61 & 0 \\
\hline 3. Delaware & 11 & 8.79 & 50 & 7.32 & 0.49 & 0.49 \\
\hline 4. Auglaize & 12 & 6.55 & 64 & 2.18 & 2.18 & 2.18 \\
\hline \multirow{3}{*}{$\begin{array}{l}\text { 5. Putnam } \\
\text { Coshocton } \\
\text { Athens }\end{array}$} & 13 & 8.89 & 49 & 5.92 & 2.96 & 0 \\
\hline & 13 & 8.19 & 52 & 5.46 & 2.73 & 0 \\
\hline & 13 & 19.75 & 16 & 13.67 & 4.56 & 0 \\
\hline
\end{tabular}

*The waivered provider ranking assigns each county in order of the highest to lowest waivered provider densities (1=highest density, $88=$ lowest density).

Moreover, most waivered practitioners in Ohio were physicians, despite the federal policy that aims to expand prescribing capacity to include NPs and PAs. One reason may be that many steps are required before finally receiving the waiver such as qualification trainings ${ }^{5,17}$ and certification trainings that lasts at least 8 hours for physicians and 24 for NPs/PAs. ${ }^{17}$ Despite a physician shortage and a low supply of DATA providers in the state, Ohio currently has some of the most restrictive scope of practice laws in the country to limit the practice of NPs. ${ }^{18}$ Without widening scope of practices for NPs and PAs, the low supply of DATA providers will likely continue in the state, posing a challenge to meet the care needs of the opioid epidemic. A few limitations are noteworthy. First, missing values in provider type for some providers in the SAMHSA database is a challenge to accurately describe provider demographics. Moreover, only data of listed waivered providers were available for this study, yet the local supply does not warrant MAT treatment appointments close to where patients live. ${ }^{19}$ Additionally, as many as 70000 opioid overdose deaths have been unreported or misclassified between 1999-2015.20 Reporting inefficiencies could have influenced observed overdose deaths in Ohio counties and the magnitude of the opioid burden. Lastly, this study employed prepandemic data from 2019. The coronavirus disease 2019 (COVID-19) brought an unprecedented mental health crisis and a $30 \%$ increase in drug overdose deaths. ${ }^{21}$ Future research may replicate this study utilizing postpandemic data to see if the pandemic changed the opioid burden in counties and the provider capacity necessary to address needs.

\section{PUBLIC HEALTH IMPLICATIONS}

The inefficiency of many waivered providers to practice where patients are in the most need may help inform future city planners and health systems to place a higher emphasis on high need regions when implementing new treatment programs and allocating funds. Strategies to recruit PCPs to health professional shortage areas may prove effective, as these regions often see higher opioid burdens. Moreover, county-level maldistributions between opioid burden and waivered provider supply demonstrate the presence of different mechanisms producing variabilities in opioid deaths. Providers and hospital systems should account for this variability by implementing community level initiatives that best serve their counties, as a one size fits all approach may not alleviate substance abuse. The lower supply of NPs and PAs as waivered providers suggests initiatives to encourage NPs and PAs to obtain a waiver may increase prescribing capacity among treatment programs and provide relief to both physicians and patients. Further reforming Ohio scope of practice agreements to enable NPs and PAs to treat patients without physician involvement and receive independent prescribing authority may reduce barriers to involve these clinicians in MAT. Ohio counties in this study that reported higher overdose rates ( $>38.3$ per 100000 ) and lower provider densities $(<13.9$ per 100000$)$ than the state average should be given special consideration when incentivizing the location of practices providing MAT. These regions may be eligible for special mental health professional shortage area (HPSA) designations and may leverage loan repayment programs to recruit providers. 


\section{REFERENCES}

1. 2019 Drug Overdose Death Rates. Centers for Disease Control and Prevention. June 23, 2021. Accessed July 14, 2021.

https://www.cdc.gov/drugoverdose/deaths/2019.html

2. Rembert M, Betz M, Partridge M. Taking Measure of Ohio's Opioid Crisis. The Ohio State University: Swank Program in Rural-Urban Policy; 2017.

3. National Academies of Sciences, Engineering, and Medicine, Health and Medicine Division, Board on Health Sciences Policy. MedicationAssisted Treatment for Opioid Use Disorder: Proceedings of a Workshop-in Brief. National Academies Press (US); 2018. Accessed July 14, 2021.

http://www.ncbi.nlm.nih.gov/books/NBK534504/

4. MAT Medications, Counseling, and Related Conditions. SAMHSA. August 9, 2020. Accessed January 25, 2021.

https://www.samhsa.gov/medication-assisted-treatment/medications -counseling-related-conditions

5. Become a buprenorphine waivered practitioner. SAMHSA. May 14, 2021. Accessed June 25, 2021.

https://www.samhsa.gov/medication-assisted-treatment/becomebuprenorphine-waivered-practitioner

6. Comprehensive Addiction and Recovery Act of 2016; 2016. https://www.govinfo.gov/app/details/PLAW-114publ198

7. Haffajee RL, Lin LA, Bohnert ASB, Goldstick JE. Characteristics of US counties with high opioid overdose mortality and low capacity to deliver medications for opioid use disorder. JAMA Netw Open. 2019;2 (6):e196373.

https://doi.org/10.1001/jamanetworkopen.2019.6373

8. Ghertner, R. US trends in the supply of providers with a waiver to prescribe buprenorphine for opioid use disorder in 2016 and 2018. Drug Alcohol Depend. 2019;204:107527.

https://doi.org/10.1016/j.drugalcdep.2019.06.029

9. Rosenblatt RA, Andrilla CHA, Catlin M, Larson EH. Geographic and Specialty Distribution of U.S Physicians Trained to Treat Opioid Use Disorder. Ann Fam Med. 2015;13(1):23-26.

https://doi.org/10.1370/afm.1735

10. Buprenorphine Practitioner Locator. SAMHSA. Accessed 2019. https://www.samhsa.gov/medication-assisted-treatment/practitioner -program-data/treatment-practitioner-locator

11. Ohio Drug Overdose Deaths. County Health Rankings \& Roadmaps. Published 2019. Accessed July 14, 2021.

https://www.countyhealthrankings.org/app/ohio/2019/measure/ factors/138/data

12. US Census Bureau Quickfacts: Ohio. United States Census Bureau. Published 2019. Accessed January 25, 2021.

https://www.census.gov/quickfacts/fact/map/OH/IPE120219

13. Akoglu H. User's guide to correlation coefficients. Turk JEmerg Med. 2018;18(3):91-93. https://doi.org/10.1016/j.tjem.2018.08.001

14. Langabeer JR, Stotts AL, Cortez A, Tortolero G, Champagne-Langabeer T. Geographic proximity to buprenorphine treatment providers in the US. Drug Alcohol Depend. 2020;213:108131. https://doi.org/10.1016/j.drugalcdep.2020.108131

15. Parran TV, Muller JZ, Chernyak E, et al. Access to and payment for office-based buprenorphine treatment in Ohio. Subst Abuse.
2017;11:1178221817699247.

https://doi.org/10.1177/1178221817699247

16. Primary care health professional shortage areas (HPSAs). KFF. November 5, 2020. Accessed July 14, 2021.

https://www.kff.org/other/state-indicator/primary-care-healthprofessional-shortage-areas-hpsas/

17. SAMHSA. Medication-Assisted Treatment - Factsheet . Published online March 2018.

https://www.mnmed.org/getattachment/advocacy/Key-Issues/

Prescription-OpioidTask-Force/Resources-for-physicians/

MedicationAssistedTreatmentFACTSHEET-3-29-FINAL-

VERSION.pdf.aspx?lang=en-US

18. Nurse practitioner scope of practice laws. KFF. May 24, 2015. Accessed July 14, 2021.

https://www.kff.org/other/state-indicator/total-nurse-practitioners/

19. Flavin L, Malowney M, Patel NA, et al. Availability of buprenorphine treatment in the 10 states with the highest drug overdose death rates in the United States: J Psychiatr Pract. 2020;26(1):17-22. https://doi.org/10.1097/PRA.0000000000000437

20. Buchanich JM, Balmert LC, Williams KE, Burke DS. The effect of incomplete death certificates on estimates of unintentional opioid-related overdose deaths in the United States, 1999-2015. Public Health Rep. 2018;133(4):423-431. https://doi.org/10.1177/0033354918774330

21. CDC. Drug Overdose Deaths in the US Up 30\% in 2020. Centers for Disease Control and Prevention, National Center for Health Statistics. September 7, 2021. Accessed November 19, 2021. https://www.cdc.gov/nchs/pressroom/ nchs_press_releases/2021/20210714.htm 